\title{
PRÁXIS E FORMAÇÃO DA PERSONALIDADE: UMA INCURSÃO NO PENSAMENTO LUKACSIANO
}

\section{PRAXIS AND FORMATION OF PERSONALITY: NA IN THOUGHT INCURSION LUKACSIAN}

Epitácio Macário ${ }^{1}$

\section{Resumo}

O artigo procura evidenciar a relação ente práxis e formação da personalidade na perspectiva do pensamento de Gyorgy Lukács. A caracterização do trabalho e da práxis social conduz à constatação de que a ação do homem sobre a natureza e a sociedade é transformadora e opera decisões entre alternativas. A personalidade constitui-se da cadeia de decisões operadas pelos indivíduos durante suavida.

Palavras-Chave: Trabalho - Práxis Social - Individualidade - Personalidade

\begin{abstract}
The article tries to show the relation between praxis and the formation of personality from the perspective of thinking of Gyorgy Lukacs. The characterization of work and social praxis leads to the conclusion that the action of man over nature and society is transforming and operating decisions between alternatives. The personality is made up of the decision chain operated by individuals during their lifetime.
\end{abstract}

Keywords: Labour - Social Praxis - Individuality - Personality

\section{Introdução: trabalho e práxis social}

O homem é um ser automediador da natureza na medida em que sua atividade específica é consciente. O comparecimento da consciência proporciona que as atividades humanas sejam representadas mentalmente e com isto seja possível estabelecer, abstratamente, finalidades e meios de efetivação prática. Isto quer dizer que, pelo concurso da consciência, o homem toma sua atividade e o objeto dela como pergunta, como problema, não se identificando imediatamente com ambos - como é o caso dos animais. ${ }^{2}$ É nisso que radica a possibilidade efetiva da transformação, isto é, o ser natural 
homem pode tomar uma fração da natureza, senão todo o mundo exterior, como objeto de sua vontade. Somente porque a atividade com que o homem intercambia com o meio exterior é consciente, ele pode produzir objetos úteis sobre a base daquilo que a natureza oferece. Ser automediador tem, primeiramente, este significado: que um ser natural (o homem enquanto existência corpórea, objetiva) desencadeia um processo de transformação dos objetos com os quais se defronta (o meio natural) em seu próprio benefício, e só o faz porque é capaz de tomar todo o mundo objetivo e sua própria atividade como objeto de sua vontade.

Todavia, a ação que o homem desencadeia sobre o mundo exterior age sobre ele mesmo, operando transformações em si mesmo. Esta dialética da transformação do meio e de si mesmo é expressa por Marx (1983, p. 149), de maneira irretorquível, quando trata do trabalho na sua forma especificamente humana:

\begin{abstract}
Antes de tudo, o trabalho é um processo entre o homem e a Natureza, um processo em que o homem, por sua própria ação, media, regula e controla seu metabolismo com a Natureza. Ele mesmo se defronta com a matéria natural como uma força natural. Ele põe em movimento as forças naturais pertencentes à sua corporalidade, braços e pernas, cabeça e mão, a fim de apropriar-se da matéria natural numa forma útil para sua própria vida. Ao atuar, por meio desse movimento, sobre a Natureza externa a ele e ao modificá-la, ele modifica, ao mesmo tempo, sua própria natureza. Ele desenvolve as potências nela adormecidas e sujeita o jogo de suas forças a seu próprio domínio.
\end{abstract}

Ora, o homem regula sua atividade sobre o meio externo, arrancando dele coisas, objetos (valores de uso) que não poderiam brotar da espontaneidade do movimento natural. Esta mesma atividade realiza mudanças nas forças naturais do homem, desenvolvendo capacidades que estavam adormecidas, engendrando novas habilidades e aptidões. Da mesma forma que a atividade consciente apropria-se das forças naturais dos objetos externos para pô-las segundo a vontade do homem, ao se efetivar ela implica que o homem controle suas forças tendo em vista o fim almejado. $O$ desenvolvimento do trabalho resulta, assim, no avanço do controle sobre as forças da natureza externa e, ao mesmo tempo, no controle sobre as potências 
naturais do próprio homem, controle dos instintos biologicamente fundados. ${ }^{3}$ Este desenvolvimento das forças naturais do homem e o conseqüente tomar consciência de tais é o segundo aspecto do conceito do homem como ser automediado da natureza.

É necessário ainda citar que a atividade consciente (o trabalho e toda forma de práxis) é estruturalmente social, ou seja, ela sempre se efetiva mediada por uma forma particular de cooperação social. Com efeito, o trabalho na sua forma especificamente humana, pressupõe um modo de vida gregário em que as atividades vitais são divididas e combinadas. ${ }^{4}$ É esta a raiz do florescimento de um conjunto de atividades que já não se dirigem diretamente à transformação da natureza, mas se dedicam à organização da vida comunitária, da vida social. Dito de outro modo: a produção dos valores de uso pelo trabalho pressupõe a ativação de relações sociais, relações que, sendo ativas e não simplesmente guiadas por instintos biológicos, consistem em atividades conscientes que instauram a reciprocidade social. Compreendemos estas relações como complexos de atividades que tem o homem/sociedade como objeto, razão porque chamamo-las - em consonância com Lukács - de práxis social. Trata-se de atividades que mediam as relações recíprocas entre os homens, entre o homem singular e o gênero e entre o homem e sua essência. $^{5}$

Automediar-se com a natureza e com a realidade social significa, portanto, que o homem integra o quadro destas realidades, é parte delas; porém, é parte ativa cuja atuação imprime mudanças em si mesmo e na própria materialidade (natural e social). No escopo da atividade consciente, ele (o homem) desencadeia um processo sempre dinâmico de apropriação subjetiva dos conteúdos naturais e sociais, bem como opera escolhas entre alternativas objetivamente existentes. No trabalho, o homem tem de confrontar a finalidade estabelecida mentalmente - finalidades que ao fim e ao cabo respondem a necessidades postas pelo desenvolvimento social - com as condições materialmente existentes (na natureza) e decidir quais possibilidades operar. $O$ êxito ou fracasso da atividade será provado pelo objeto criado, se provido ou desprovido de utilidade. É assim que se engendram os valores de uso voltados 
a prover necessidades do homem/sociedade. É assim, também, que se funda o dever-ser como norma orientadora da ação do homem tendo em vista alcançar um fim específico - no caso, um produto que responda a necessidades postas pela sociedade onde o homem vive e se reproduz. Na medida em que o método utilizado, o modus operandi, a forma de realização das atividades laborais resultam em sucesso ou em fracasso, vão-se fundando e generalizando normas que assumem a forma de dever-ser no plano da subjetividade.

O mesmo ocorre no terreno da práxis social, sendo que, neste caso, os valores já não são materializados em coisas (valores de uso), mas assumem a forma de valores espirituais. Inobstante, eles são processados segundo a sua "utilidade" para as forças que disputam a hegemonia do metabolismo social. Eles expressam, no plano espiritual, relações concretamente existentes, sedimentando-se na esfera do habitus, no complexo da moral, da estética e da ética. A consciência apropria-se destes valores, transformando-os no dever-ser que parametriza e orienta a ação do homem no mundo social. Ocorre aqui, mutatis mutandi, um símile do que acontece no trabalho: na práxis social, os indivíduos fazem escolhas sempre em face das possibilidades concretamente existentes e orientados por um dever-ser que expressa, subjetivamente, valores enraizados na materialidade das relações sociais.

\section{Práxis, generidade e individualidade}

A conduta do homem para com o seu meio, natural e social, é ativa. Através do trabalho ele interfere na ordem causal da natureza fazendo brotar das premissas existentes formas de objetividade totalmente novas. Por meio da práxis social, os homens objetivam relações sociais, complexos mediadores, instituições, que esteiam a própria sociedade. O conjunto das objetivações oriundas do trabalho e da práxis social constitui o mundo essencialmente humano, o gênero humano. Como tal, o gênero tem uma existência objetiva, que ultrapassa a interioridade do indivíduo e evolui segundo leis próprias. 
Porém, e este é o outro lado, trata-se de uma forma de realidade engendrada pelos atos teleológicos dos indivíduos. Assim, pois, o surgimento e evolução do gênero humano - e a reprodução da sociedade em cada momento histórico só pode ocorrer pela mediação da ação dos indivíduos. São estas ações que se sintetizam no fluxo das relações travadas no trabalho e na práxis social, dando origem a uma dinâmica que vai além das posições teleológicas singulares. As relações assim fundadas sobre atos teleológicos assumem legalidade própria e se mostram como objetividades, como causalidades postas relativamente independentes da vontade dos indivíduos singulares. ${ }^{6}$

Assim, indivíduo e sociedade constituem dois pólos ontologicamente diferentes cuja existência e evolução se processam um por meio do outro. Nesta dinâmica de transformação da generidade em individualidade e viceversa, as leis que presidem a totalidade é que exercem o papel de momento predominante, sem que isto diminua o papel ativo do indivíduo na sociedade.

O gênero humano consiste, pois, no acúmulo e fixação dos fatores que se mostraram essenciais no curso da experiência humana. Trata-se das capacidades e forças produtivas, dos conhecimentos e saberes, dos valores e bens simbólicos que se fixaram e constituem a memória da evolução histórica das sociedades humanas. A continuidade da experiência humana já não se fixa no código genético dos exemplares da espécie como uma sua dimensão biológica, consoante acontece com os demais seres vivos. Ela se fixa e acumula em vetores externos aos indivíduos: nas relações sociais, na linguagem, nos instrumentos, nas instituições sociais (educação, por exemplo), nos conhecimentos sobre a natureza e a sociedade, nos valores espirituais materializados nos costumes, na moral, na ética. ${ }^{7}$

Ora, o que são estes vetores materiais que conservam a experiência humana senão algo que se ergue das sínteses relacionais das posições teleológicas que foram resolvidas com êxito e engastaram-se no continuum social? Com efeito, se o desenvolvimento da sociedade é que põe as necessidades e delimita concretamente o espaço das perguntas e respostas possíveis, não menos verdade é que os indivíduos reagem a tal quadro ativamente, pondo novas finalidades, escolhendo dentre as alternativas 
presentes aquela mais adequada ao fim posto idealmente e realizando-a praticamente.

É bem verdade que todo ato de objetivação implica que o indivíduo incorpore a experiência passada como premissa necessária à realização do fim posto no presente. Porém, na medida em que ele se põe diante de problemas novos e mutáveis, postos em circunstâncias sempre novas, - problemas aos quais tem de responder sob pena de ruína -, aquilo de que se serviu como base para sua ação (o conhecimento, os valores predominantes) é reelaborado em face dos novos desafios postos no presente. Ademais, todo ato de objetivação (no trabalho e na práxis social) se realiza sobre um conhecimento prévio, mas, como já vimos, adentra o desconhecido trazendo à vida novos conhecimentos. Uma vez respondido o problema de forma exitosa, as novidades adquiridas no curso da objetivação reentram no continuum social, desenvolvendo as forças da sociedade como um todo, ou as forças do gênero. É assim que se processa a continuidade na reprodução do ser social: como movimento bipolar onde a sociedade (ou o grau de ser mais imediato, a classe, por exemplo) põe as necessidades e delimita o campo das possibilidades de resposta e os indivíduos reagem a estes condicionamentos de forma ativa, escolhendo entre as alternativas possíveis. Ela se processa, pois, numa dinâmica que reproduz o já adquirido, impulsionando-o para além de si mesmo; trata-se de um movimento caracterizado pela permanência na contínua mudança. Nas palavras de Lukács:

A continuidade (...) não é jamais um simples manter fixo aquilo que já foi alcançado, mas também, sem que cesse este trabalho de fixação, um ininterrupto progredir para além, e esta dialética da superação, a unidade contraditória do conservar e do proceder adiante, opera em todos os estágios. (1981, p. 198).

Compreende-se, desta forma, que mesmo a reiteração do modelo social presente não é um mero afirmar-se da lei geral sobre as consciências dos indivíduos. Trata-se, antes, de um processo muito ativo, onde os indivíduos acolhem a pressão social - geralmente exercida de forma anônima e por meio de muitas mediações - transformando-a nas finalidades que orientam suas 
escolhas alternativas no seu agir cotidiano. Da mesma forma e com o mesmo grau de necessidade, o reforçamento das tendências de mudança desabrochadas na dinâmica social encontra nas finalidades, nas escolhas e nos atos operados pelos indivíduos seu momento vivificante. Nesse sentido, a práxis constitui o motor do processo social, seja ela reiterativa ou transformadora, processada por meio das escolhas e dos atos dos indivíduos singulares. Em todo o caso, a apropriação das forças acumuladas no plano genérico e seu processamento por meio dos atos individuais é uma condição irrevogável, tanto do ponto de vista da reprodução da sociedade quanto da formação da individualidade.

\section{Práxis, individualidade e personalidade}

O que se expôs até aqui permite afirmar que o desenvolvimento da individualidade está na razão direta da apropriação ativa das forças e potências engendradas no plano genérico. A organização biológica, os elementos genéticos, os instintos, continuam como base ineliminável da existência e evolução da individualidade. Todavia, esta base é transformada, ela mesma, através da apropriação daquelas objetivações que constituem o gênero humano - o mundo da cultura, se assim se quiser. Por isto, a incorporação destes elementos na esfera da individualidade - algo que se processa mediado pela práxis do homem no mundo - consiste no momento predominante do processo de individuação. Com efeito, os próprios instintos e sentidos são engastados num processo de humanização precisamente e na medida em que, através da práxis, os homens acolhem em si uma cada vez mais extensa malha de categorias essencialmente sociais, recobrindo aqueles elementos puramente biológicos. $^{8}$

A práxis é, pois, a mediação pela qual os indivíduos se apropriam da generidade, tornam-se humanos à proporção que humanizam seus próprios sentidos, suas pulsões e potências biológicas. Neste mesmo ato, eles transformam o mundo exterior, a natureza e a sociedade. Nas belas palavras de Lukács: 
Desde o primeiro trabalho, como gênese da humanização do homem, até as mais sutis decisões psicológicas e espirituais, o homem constrói o seu mundo externo, contribui para edificá-lo e aperfeiçoá-lo e, ao mesmo tempo, com estas mesmas ações, constrói a si mesmo, passando da mera singularidade natural à individualidade no interior de uma sociedade (1981, p. 261).

Mas aqui é preciso retomar um aspecto da questão já levantado. A práxis do indivíduo, as finalidades e as escolhas que realmente se efetivam, não se dão num vazio de determinações. Pelo contrário, o indivíduo age em circunstâncias bem determinadas. E estas determinações constituem, precisamente, as mediações por meio das quais ele se apropria do patrimônio genérico. Quer-se dizer que entre a esfera individual e a genérica interpõe-se um conjunto complexo de relações socialmente estabelecidas que determina, com força de lei, o lugar e a posição de cada um no gradiente da divisão social do trabalho, bem como seu pertencimento a uma classe ou segmento de classe. Este fato não é inócuo para o processo de individuação porque ele condiciona a apropriação desigual do patrimônio genérico, rebaixando as possibilidades concretas de evolução e enriquecimento (material e espiritual) dos trabalhadores em benefício do acúmulo privado de riqueza do lado da burguesia e submetendo ambos à alienação.

A divisão social do trabalho e sua forma mais evoluída - a segmentação da sociedade em classes estruturalmente antagônicas - delimita concretamente o espaço de reprodução das individualidades, põe as necessidades e possibilidades a que os indivíduos reagem ativamente. A classe não suprime as singularidades dos indivíduos, não os dissolve numa massa homogênea, mas põe, efetivamente, as condições gerais sobre as quais os indivíduos desenvolvem sua práxis, realizam suas escolhas.

A individualidade carrega, assim, as marcas destas circunstâncias que, afinal, fornecem o material e os meios de sua atividade. Se tomarmos a própria organização biológica, os instintos, as pulsões naturais dos indivíduos enquanto possibilidades, veremos que algumas se tornam ato e outras são preteridas, permanecendo no seu em si como mera possibilidade. O grau de desenvolvimento das forças produtivas e das relações sociais, bem como a classe à qual pertence o indivíduo é que fornecerá as possibilidades concretas 
da atualização destas potencialidades. Pensamos nas premissas biológicas do ouvido musical, da desteridade e sensibilidade da mão e dos dedos para a execução de um piano; elas podem estar dadas no próprio corpo do indivíduo, mas sua efetivação e desenvolvimento dependerão das possibilidades materiais para o exercício e o cultivo de tal potência. As circunstâncias sociais podem atuar no sentido de facilitar ou obstaculizar o desenvolvimento destas potencialidades.

Por outro lado, o encadeamento de sons formando melodias, o instrumento musical (o piano) e os conhecimentos e habilidades necessárias à execução do instrumento já não são dimensões inscritas no indivíduo, mas criações puramente sociais que existem fora dele. Para incorporá-las em suas faculdades subjetivas, o indivíduo desenvolve uma atividade pela qual - e sempre por meio dos outros indivíduos - reproduz em si as faculdades objetivadas no próprio instrumento musical, faculdades que são resultado de toda a história passada da sociedade. ${ }^{9}$ As potências naturalmente dadas fornecem a base para a apropriação, por parte do indivíduo, da capacidade gerada socialmente (conhecimentos, habilidades, modus operandi). Como tal, constituem uma dimensão ineliminável do homem, mas no curso de sua efetivação por meio da práxis do indivíduo estas dimensões acolhem em si características puramente sociais, características estas que, ao fim e ao cabo, definem o caráter, a direção, a forma e o conteúdo de tais potencialidades.

Não é demais recordar que as possibilidades de acesso e cultivo destas habilidades, bem como a existência de pianos é uma determinação da sociedade e já não depende das potências naturais do indivíduo. Há, desta forma, uma clara e inequívoca determinação social da individualidade, o que permite a Lukács afirmar:

(...) ainda quando pensa agir por impulso de suas necessidades internas - nas suas ações e nos seus pensamentos, sentimentos etc. que as preparam, acompanham, aprovam e criticam - o homem dá sempre respostas práticas a dilemas práticos da vida que, todas às vezes, uma sociedade determinada (no imediato: a classe, o estamento etc. descendo até a família) Ihe põe enquanto indivíduo que nela vive. Do momento do nascimento até o túmulo, esta obra determinativa - o campo para a resposta definido pela pergunta - não cessa nunca. (1981, p. 263) 
Esta tese rompe com o princípio do liberalismo que centra todo o processo social no indivíduo, eclipsando os condicionamentos macroestruturais ou então concebendo estes como simples derivação da escolha racional dos indivíduos tomados no seu isolamento. Consiste, ainda, numa crítica ferrenha das doutrinas imanentistas que concebem o processo evolutivo da individualidade como mero desdobrar de potenciais já presentes numa essência não histórica inerente ao indivíduo. Para estas concepções, a formação da individualidade não ultrapassa o caráter de um processo através do qual as potencialidades (a vocação, por exemplo) inscritas no indivíduo já no nascimento vão amadurecendo, aperfeiçoando-se no curso de sua vida. Para Lukács, e para todo o marxismo, o mundo humano é objetivado, é criado pela práxis dos homens em sociedade. Porquanto, o indivíduo se forma enquanto pertencente ao gênero humano ao fazer deste mundo objetivo, ao fazer dos objetos humanizados uma sua faculdade subjetiva. Talhada assim, a crítica marxista supera tanto a perspectiva liberal e essencialista quanto o materialismo mecanicista para quem o indivíduo é resultado direto e mecânico das circunstâncias.

Por outro lado, também não devemos esquecer que, cada uma de tais reações de um indivíduo ao seu ambiente social (inclusive a troca orgânica da sociedade com a natureza), tem sempre um caráter alternativo, compreende sempre em si, inevitavelmente, um sim ou um não (ou um 'voto de abstenção') frente à demanda posta pela sociedade (Idem., ibidem.)

O filósofo marxista opera, desta forma, uma superação dialética de ambos os pólos, repisando o tertium datur já instaurado por Marx expresso no postulado segundo o qual o homem faz a história, mas não em circunstâncias por ele escolhidas. Com efeito, a individualidade só pode ser pensada como processo formado pelas decisões assumidas e praticamente realizadas pelos indivíduos, decisões que se efetivam sobre possibilidades postas pela reprodução social como um todo ou pelo grau de ser no qual o indivíduo se reproduz. 
A substância do indivíduo se constrói, pois, no curso de sua práxis, vale dizer, no fluxo das escolhas que ele opera durante a vida. Seu caráter define-se pelos tipos de escolhas que transforma em prática nas intermitentes e incontornáveis respostas que tem de articular em face dos imperativos postos pelo meio onde vive e se reproduz (a natureza e a sociedade). É isto que afirma o pensador húngaro:

\begin{abstract}
Em cada indivíduo é latente um grande número de possibilidades /.../ mas seu verdadeiro caráter se realiza /.../ justamente quando e porque se traduz em ato uma certa possibilidade, e não outra. Naturalmente, mesmo a possibilidade enquanto tal faz parte do quadro complexivo do indivíduo, já que a sua superação é, também ela, objeto de uma decisão alternativa; mas determinante permanece a questão: ela é acolhida ou negada? Torna-se ação ou permanece uma mera possibilidade, definitivamente condenada a não se tornar operante? A substância de um indivíduo é, portanto, aquilo que no curso da sua vida se compõe como continuidade, direção, qualidade da ininterrupta cadeia destas decisões (Lukács, 1981, p. 262. Negritos nossos).
\end{abstract}

As decisões objetivadas pelo indivíduo no curso de sua vida constituem o momento definidor da sua substância, do ser-preciamente-assim da sua individualidade. É precisamente este decidir entre alternativas reais que particulariza os indivíduos, que os diferencia uns dos outros. Com efeito, a própria constituição biológica singulariza os indivíduos, instaura-os como organismos irrepetíveis, cujas pulsões e sentidos só podem ser diferentes, singulares. Por isto a forma de sensibilizar o mundo exterior e com ele se relacionar, a forma de reagir aos constrangimentos postos pela sociedade ou dados pelo meio natural, já incorpora uma diferença elementar dada nos atributos instintivos primários. Mas, como vimos, estas pulsões se exercem mediadas por categorias puramente sociais, isto é, a sociedade é que põe o material e os meios de efetivação das forças e potências do homem. Para realizar praticamente estas potencialidades, o homem desenvolve uma atividade sobre as condições oferecidas pelo meio no curso da qual ele tem de dirigir seus próprios instintos, direcionar sua vontade, lutar contra aquilo que há nele de puramente biológico para adequá-los à finalidade, ao dever-ser vinculado ao fim almejado. 
Com isto, aquilo que preside a diferença no plano biológico, instintivo, vai sendo recoberto por conteúdos puramente sociais. Noutras palavras, a diferenciação entre os indivíduos deixa de ser puramente natural e assume um caráter essencialmente social na medida em que as possibilidades de exercício das potências individuais são postas pela sociedade e as faculdades subjetivas vão se formando no ininterrupto processo de objetivação da práxis desses indivíduos.

Por meio da práxis (que pressupõe realização prática de escolhas singulares), os indivíduos reentram na esfera da generidade mediados pelo conjunto de relações sociais que estabelecem as condições de efetivação das suas escolhas. Ao mesmo tempo, as relações que condicionam a práxis individual consistem nos dutos dinâmicos pelos quais as energias e forças do gênero se particularizam e fecundam a dimensão individual. Como tais, estas relações constituem um campo de mediações (a particularidade) às quais os indivíduos reagem decidindo entre alternativas.

O fato, pois, de pertencerem à mesma particularidade (a classe, o segmento de classe, o ambiente sócio-cultural etc.) não elimina a diferença entre os indivíduos, na medida em que, em seus atos, eles operam escolhas singulares que impactam de maneira diferente as faculdades subjetivas. Estas decisões desencadeiam transformações de profundidade nos sentidos subjetivos, instaurando assim uma forma ímpar de singularidade mediada socialmente, a personalidade. Esta é tão mais desenvolvida e afirmada, quanto mais o indivíduo é capaz de tomar suas potências interiores e as circunstâncias históricas como objeto de reflexão e decisão consciente. Refletindo sobre as decisões tomadas pelo indivíduo como móvel de sua formação, a filósofa Ester Vaisman (2009, p. 456) afirma:

Vale dizer, mesmo que tais decisões sejam tomadas em meio às possibilidades efetivamente existentes, e não a partir de uma "vontade transcendental", tais decisões carregam aspectos diretamente vinculados à subjetividade que as tomou. É nessa medida que nos sentimos autorizados a afirmar que a dimensão mais relevante da formação da individualidade é sua autoconstituição, pois se trata, finalmente, de um só e único processo que diz respeito tanto à constituição do gênero quanto do indivíduo, no interior do qual a 
dimensão ativa, que é atributo específico da existência humana, se encontra circunscrita apenas pelo próprio indivíduo.

Segundo este ponto de vista, a essência do indivíduo, seu caráter, sua personalidade, não podem mais ser buscados em esferas extra-mundanas ou numa generidade manifestada imediatamente no indivíduo (Feuerbach), nem na pura interioridade, tampouco numa ação mística exercida pelo meio sobre o homem. A individualidade e a personalidade edificam-se no curso da ação prática que o homem exerce sobre as circunstâncias postas pela dinâmica social e pela relação da sociedade com a natureza. Com isto a afirmação do materialismo dialético segundo a qual o homem é o processo dos seus atos é substantivada.

\section{Referências Bibliográficas}

DUARTE, N. A individualidade para-si: contribuição a uma teoria históricocrítica da formação do indivíduo. 2. ed. Campinas/SP: autores Associados, 1999.

LEONTIEV, A. O desenvolvimento do psiquismo. Portugal: Livros Horizonte, 1978.

LESSA, S.. Mundo dos homens - trabalho e ser social. São Paulo: Boitempo, 2002.

LUKÁCS, G. II lavoro. In: Per l'ontologia dell'essere sociale. Roma: Riuniti, 1981a.v. 2, p.11-131(Traduzido para o Português pelo prof. Ivo Tonet). . La riproduzzioni. In: Per l'ontologia dell'essere sociale. Roma: Riuniti, 1981b. v. 2, p. 135-331 (Traduzido para o Português pelo prof. SérgioLessa).

. Ontologia do ser social: os princípios ontológicos fundamentais de Marx. Tradução de Carlos Nelson Coutinho. São Paulo: Livraria Editora Ciências Humanas, 1979.

. O jovem Marx e outros escritos de filosofia. Tradução de Carlos Nelson Coutinho e José Paulo Netto. Rio de Janeiro: Editora da UFRJ, 2007.

MARX, K. Manuscritos econômico-filosóficos. Lisboa: Edições 70, 1975.

. Para a crítica da economia política. Trad. Edgard Malagod et al. São Paulo: Abril Cultural, 1982.

. O capital. Livro primeiro, V. I. São Paulo: Abril Cultural, 1983.

. Formações econômicas pré-capitalistas. Introdução de Eric Hobsbawm. Trad. João Maia. $6^{2}$ ed. São Paulo: Paz e Terra, 1991.

MARX, K. e ENGELS, F. A ideologia alemã. Organizado e traduzido por Marcelo Backes. Rio de Janeiro: Civilização Brasileira, 2007. 
VAISMAN, E. Marx e Lukács e o problema da individualidade: algumas aproximações. In: Revista Perspectiva, v. 27, n. 2, Florianópolis/SC: UFSC, jul-dez de 2009 (p. 441-459).

\footnotetext{
${ }^{1}$ Professor de Economia Política e Filosofia do Trabalho na Universidade Estadual do Ceará. Email: macarius@oi.com.br

${ }^{2}$ Cf. Marx (1975, p. 164-65): "O animal identifica-se imediatamente com a sua atividade vital. Não se distingue dela. É a sua própria atividade. Mas o homem faz da atividade vital o objeto da vontade e da consciência. Possui uma atividade vital consciente. Ela não é uma determinação com a qual ele imediatamente coincide".
}

${ }^{3}$ Cf. Lukács (1981, p. 52) que, ao analisar o ato do homem de lapidar uma pedra para utilizá-la como instrumento, afirma: "(...) aquilo que acontece com o ser natural da pedra (...), acontece também com os seus movimentos etc., na sua origem biológico-instintivos. $\mathrm{O}$ homem deve pensá-los expressamente para aquele determinado trabalho e executá-los em contínua luta contra aquilo que há nele de meramente instintivo, contra si mesmo".

${ }^{4} \mathrm{O}$ gregarismo que está na origem do homem foi uma condição para o surgimento do trabalho na forma especificamente humana, conforme Marx (1991, p. 66): "[a] comunidade tribal espontânea ou, se preferirmos dizer, a horda constitui o primeiro passo para a apropriação das condições objetivas de vida, bem como da atividade que a reproduz e the dá expressão material, tornando-a objetiva (atividade de pastores, caçadores, agricultores etc.)."

${ }^{5} \mathrm{Na}$ sexta tese sobre Feuerbach Marx e Engels (2007) escrevem: "Feuerbach dissolve a essência religiosa na essência humana. Mas a essência humana não é uma abstração inerente ao indivíduo singular. Em sua realidade ela é o conjunto das relações sociais.

${ }^{6}$ A dinâmica social, suas leis e regularidades têm sua origem nos atos teleológicos dos indivíduos, mas, na sua globalidade, o processo social exibe um claro e inequívoco caráter causal. Quer-se dizer com isto que não há, nem pode haver, uma teleologia presidindo o movimento global da história. Quanto a este ponto de vista, Lukács é irredutível: "Nos processos concretos, porém, não se pode encontrar nenhuma força motriz teleológica. Em cada etapa singular, e na passagem àquela sucessiva [passagem de uma esfera ontológica a outra; passagem de uma formação social a outra], podem ser identificadas somente conexões causais e as interações que elas constituem. Até no ser social, onde sem dúvida as posições teleológicas singulares operadas pelos homens têm caráter teleológico, as suas interações reais têm sempre um caráter causal puro. A essência destas posições teleológicas /.../consiste precisamente em colocar em movimento cadeias causais cujas conseqüências - causalmente determinadas - vão muito além do conteúdo da posição teleológica em si" (1981: 167-8).

${ }^{7} \mathrm{Na}$ produção da vida material, os homens contraem relações materiais responsáveis pelo engendramento de uma força qualitativamente diferente da soma das forças individuais: as forças genéricas. Isto se processa independentemente do conhecimento dos indivíduos, porquanto os seus interesses são delimitados pela busca de eficácia na resposta a um carecimento imediato. Por isso, a consciência subjetiva que preside os atos singulares não toma a realidade social como referência, mas ilumina, de forma mais ou menos abrangente, apenas aquele setor e aquelas circunstâncias da realidade mais diretamente ligadas à realização da finalidade específica. "Todavia - assevera Lukács - não nos esqueçamos que, se do ponto de vista da consciência subjetiva está em primeiro plano a reprodução do indivíduo particular, objetivamente os atos práticos do homem, na sua grande maioria, reentram na esfera da generidade, mesmo que este nexo não seja dado à consciência do indivíduo" (1981, p.185). Os atos singulares reentram na generidade na medida em que se sintetizam em relações objetivas. Para nosso autor, "é nestas somas e sínteses que se exprime /.../ a continuidade do social. Elas constituem um tipo de memória da sociedade, que conserva o adquirido do passado e do presente fazendo deles os veículos, as premissas, os pontos de apoio para o desenvolvimento futuro" (Idem., 186).

Isto é plasticamente verificável no plano da sexualidade, pois sua evolução através dos tempos mostra um crescimento constante de conteúdos puramente sociais que interferem, 
inclusive, sobre o erotismo, sobre a atração entre os sexos. Pense-se, por exemplo, na utilização de cosméticos, na modelação do corpo por meio de exercícios e intervenções cirúrgicas, nas formas de vestir o masculino e o feminino, nos vários tipos de fetiches arquitetados pela indústria, na venda e socialização de imagens eróticas e pornográficas através da rede de computadores. Se não for demasiadamente nostálgico, citamos, ainda, o cortejo, os rituais de namoro que constituem (constituíam?) mediações puramente sociais da relação sexual. Todos estes elementos são criações puramente sociais que interferem, profundamente, na forma e no conteúdo do erotismo e da relação sexual entre as pessoas. A base instintiva da relação entre os sexos não deixa de existir, mas é recoberta por conteúdos puramente sociais.

9 Cf. Marx (1975, p. 199): "O sentido musical do homem só é despertado pela música. A mais bela música nada significa para o ouvido completamente amusical, não constitui nenhum objeto, porque o meu objeto só pode ser a confirmação de uma das minhas faculdades. Portanto, só pode existir para mim na medida em que a minha faculdade existe para ele como capacidade subjetiva, porque para mim o significado de um objeto só vai até onde chega o meu sentido (só tem significado para um sentido que lhe corresponde). Por conseqüência, os sentidos do homem social são diferentes dos do homem associal. Só através da riqueza objetivamente desenvolvida do ser humano é que em parte se cultiva e em parte se cria a riqueza da sensibilidade subjetiva humana (o ouvido musical, o olho para a beleza das formas, em suma, os sentidos capazes de satisfação humana e que se confirmam como faculdades humanas). De fato, não são apenas os cinco sentidos, mas também os chamados sentidos espirituais, os sentidos práticos (vontade, amor, etc.), numa palavra, a sensibilidade humana e o caráter humano dos sentidos, que vêm à existência mediante a existência do seu objeto, através da natureza humanizada. A formação dos cinco sentidos é a obra de toda a história mundial anterior".

RECEBIDO EM: 08/11/2010

APROVADO EM: 30/11/2010 